\title{
VULNERABILIDADE DE TUBOS GOTEJADORES AO ENTUPIMENTO POR PRECIPITADOS QUÍMICOS DE FERRO
}

\author{
Claudionor Camilo da Costa ${ }^{1}$, Cláudio Milton Montenegro Campos ${ }^{2}$, Manuel Alves de Faria ${ }^{2}$
}

\section{RESUMO}

Objetivou-se, com o presente trabalho, verificar a intensidade da ocorrência dos precipitados químicos em cinco modelos de tubos gotejadores submetidos à irrigação com água contendo alto teor de ferro total. O sistema de irrigação foi composto de um reservatório de $1000 \mathrm{~L}$, um conjunto motobomba de $0,5 \mathrm{cv}$, um filtro de disco de 120 mesh, uma bancada de testes onde foram instaladas os tubos gotejadores. O sistema foi avaliado calculando-se a Vazão Média, Coeficiente de Variação de Vazão(C.V.Q.), Uniformidade de Distribuição/Emissão (U.D./U.E.) e Vazão Relativa (V.R.). Observou-se ao longo do experimento e no final do mesmo (ao redor de $400 \mathrm{~h}$ de irrigação) que os precipitados químicos de ferro comprometeram o desempenho de todos os tubos gotejadores, promovendo grande redução da vazão dos emissores. O grau e a intensidade de entupimento variaram conforme o modelo, notando-se que as marcas que exigiam filtração mais rigorosa ( $\mathrm{R} \mathrm{e} \mathrm{C}$ ) e aspectos construtivos semelhantes-Labirintos: R, Q e C se mostraram mais susceptíveis ao entupimento. Dentro das condições de estudo deste experimento, concluiu-se que a utilização de água com este teor de ferro total (3 mg. $\left.\mathrm{L}^{-1}\right)$ mostrou-se impraticável, podendo comprometer a irrigação.

Palavras-chave: Clogging, iron, trickle irrigation

\section{Vulnerability of drip hoses to clogging by chemical precipitates of iron}

\section{ABSTRACT}

This research aimed to verifying the intensity of chemical precipitates in five different drip hoses models on water containing a high amount of total iron. The irrigation system was assembled with one reservoir of $1000 \mathrm{~L}$, a set of motor pump of $0.5 \mathrm{cv}$, a 120 mesh filter disk, a test banch measuring where it was installed the drip hoses. The system was evaluated estimating the average flow rate, variation flow coeffícient (VFC), uniformity of distribution/emission and relative flow rate. It was possible to observe, during the days of the tests, and also at the end of the research (around $400 \mathrm{~h}$ of irrigation), that the chemical sediments of iron, deterioreted the performance of the drip hoses, promoting a great reduction in their flowing. The degree and the intensity of obstruction varied according to the model, observing that the makes which demanded more strictly filtration ( $\mathrm{R}$ and $\mathrm{C}$ ), with a similar design aspects, labyrinths: R, Q and C, showed to be more susceptible to clogging problems. In the studies conditions it could be concluded, that the utilization of water, with that total iron concentration ( 3 $\left.\mathrm{mg} . \mathrm{L}^{-1}\right)$, showed to compromise the irrigation performance.

Keywords: entupimento, ferro, irrigação por gotejamento

${ }^{1}$ Professor do Instituto Federal de Minas Gerais Campus São João Evangelista CEP 39705-000 São João Evangelista-MG. claudionor.costa@ ifmg.edu.br

2 Professor da Universidade Federal de Lavras- Departamento de Engenharia-DEG/UFLA, CEP 37200-000, CEP 37200-000 Lavras-MG. cmmcampos@deg.ufla.br; mafaria@deg.ufla.br 


\section{INTRODUÇÃO}

Um sistema de irrigação localizada bem manejado resulta na economia de água e energia. Entretanto, assume papel de suma importância para o sucesso do empreendimento a qualidade da água que será utilizada, pois a obstrução dos emissores é o maior problema associado com a operação de irrigação por gotejamento.

De acordo com Hillel (1982) e Nakayama e Bucks (1986) a qualidade da água envolve basicamente três aspectos, a saber: (1) físicos, (2) químicos e (3) biológicos. Os primeiros são determinados por partículas inorgânicas suspensas e materiais orgânicos. Sua remoção é simples, mas quando se encontram associados a lodos bacterianos, o problema é mais sério. $\mathrm{O}$ segundo envolve sólidos dissolvidos e $\mathrm{pH}$, e os últimos estão relacionados a micro e macrorganismos.Independentemente da fonte de água, os sistemas de gotejamento requerem algum tipo de filtração para remover a carga de materiais suspensos. Entretanto, isso não é suficiente para remover todas as partículas problemáticas.

Segundo Hassan (1999), o ferro e o manganês estão frequentemente presentes nas águas subterrâneas nas formas solúveis e podem precipitar. O resultado é uma grande produção de lodo e limos que pode prejudicar sobremaneira o funcionamento do sistema de gotejamento. Esses elementos podem criar problemas de entupimento a concentrações tão baixas $0,1 \mathrm{mg} \cdot \mathrm{L}^{-1}$

Para Hillel (1982), no que diz respeito ao ferro e manganês, há mais interesse nos efeitos do primeiro que do segundo, tendo-se em vista que os problemas do ferro são mais difundidos. Já se provou que o manganês pode ser tóxico a algumas culturas na mesma concentração em que ele causa entupimento.

De acordo com Hernandez e Petinari (1998), o uso de água para irrigação com teores de ferro acima de $0,5 \mathrm{mg} . \mathrm{L}^{-1}$ já merece atenção especial por parte dos projetistas, pois pode obstruir tubulações em pouco tempo e, em grau extremo, até inutilizar o sistema de irrigação.

A qualidade da água para sistemas de irrigação localizada, com relação ao entupimento, deve ser avaliada de acordo com os parâmetros apresentados na Tabela 1:

TABELA 1. Riscos de uso de águas de diferentes qualidades para irrigação localizada com relação ao entupimento.

\begin{tabular}{cccc}
\hline ELEMENTOS & \multicolumn{3}{c}{ SEVERIDADE DO PROBLEMA } \\
\hline & BAIXA & MODERADA & ALTA \\
Sólidos em suspensão $\left(\mathrm{mg} . \mathrm{L}^{-1}\right)$ & $<50$ & $50-100$ & $>100$ \\
$\mathrm{pH}$ & $<7,0$ & $7,0-8,0$ & $>8,0$ \\
Manganês $\left(\mathrm{mg} . \mathrm{L}^{-1}\right)$ & $<0,1$ & $0,1-1,5$ & $>1,5$ \\
Ferro total(mg. $\left.\mathrm{L}^{-1}\right)$ & $<0,2$ & $0,2-1,5$ & $>1,5$ \\
Sulfeto de hidrogênio & $<0,2$ & $0,2-2,0$ & $>2,0$ \\
& $<10.0$ & $10.000-50.000$ & $>50.000$
\end{tabular}

Fonte: Nakayama e Bucks (1986)

De acordo com Pizarro Cabello (1996), o risco de obstrução de um emissor depende do diâmetro mínimo do orifício de saída e da velocidade da água. Nos emissores de baixa vazão, o diâmetro de saída pode variar entre 0,3 até algo acima de $1,0 \mathrm{~mm}$. Entretanto, nos emissores de alta vazão, como microaspersores e microdifusores, os diâmetros podem chegar a mais de $2,0 \mathrm{~mm}$, nos quais o risco de obstrução é muito menor. A Tabela 2 apresenta a classificação dos emissores segundo a sensibilidade ao entupimento, de acordo com o diâmetro mínimo de saída do emissor.

Quanto maior a velocidade da água dentro da tubulação, menor o risco de sedimentação; por essa razão, prefere-se o regime turbulento ao laminar para fluxo de água em irrigação localizada.

TABELA 2. Classificação dos emissores segundo a sensibilidade ao entupimento, com base no diâmetro mínimo de passagem de água . 


\begin{tabular}{cc}
\hline $\begin{array}{c}\text { DIÂAETRO MÍNIMO } \\
(\mathbf{m m})\end{array}$ & $\begin{array}{c}\text { SENSIBILIDADE À } \\
\text { OBSTRUÇ̃̃O }\end{array}$ \\
\hline$\leq 0,7$ & Alta \\
$0,7-1,5$ & Média \\
$>1,5$ & Baixa \\
\hline
\end{tabular}

Fonte: Pizarro Cabello (1996).

\section{A uniformidade de irrigação}

Para Moraes (1984), na prática as variações de vazão dos emissores ocorrem em virtude de diversos fatores, tais como. (1) características do gotejador projetado; (2) variabilidade na sua fabricação; (3) tempo de uso; (4) perdas de carga por atrito nas tubulações da rede de distribuição; (5) diferenças topográficas na área do projeto; (6) número de gotejadores entupidos no sistema; (7) número e o grau de gotejadores parcialmente entupidos no sistema; e (8) variação na temperatura da água por todo o sistema.

De acordo com Hillel (1982), um dos fatores importantes que influenciam a Uniformidade de Distribuição/Emissão de água é o entupimento dos emissores.

Keller e Karmeli (1975) foram os primeiros a definir um percentual de uniformidade de emissão empirico para projeto de sistemas de irrigação localizada, conforme a eq.1:

U.E. $=\left[1-1,27(C V F) n^{-1 / 2}\right] \times\left(\frac{q_{n}}{q_{m}}\right) \times 100$

em que:

CVF: coeficiente de variação de fabricação; n: número de emissores por planta (mínimo de 1); qn : mínima vazão;

qm: vazão média.

Wu e Gitlin (1977) propuseram um outro parâmetro chamado variação de vazão do emissor, definido pela eq. 2 :
Qvar $=\left[1-\left(\frac{q_{n}}{q_{m}}\right)\right] x 100$

em que :

qn: vazão mínima;

qm : vazão máxima.

Merrian e Keller (1988) descreveram procedimentos de campo para medição de pressão e vazões de emissores. A uniformidade de emissão/ distribuição de campo pode ser expressa pela eq. 3:

$\mathrm{U} . \mathrm{E} . \mathrm{c}=\frac{q_{25}}{-}$

em que o numerador representa a média das $25 \%$ menores vazões medidas e o denominador, a média geral da vazões.

\section{O coeficiente de variação de fabricação (CVF)}

Com relação às imperfeições de fabricação dos emissores, Vieira (1996) cita que no dimensionamento de sistemas de irrigação localizada deve-se considerar a variabilidade existente de gotejador para gotejador, decorrentes do processo de fabricação. Dois gotejadores retirados do mesmo lote, testados à pressão $\mathrm{e}$ temperatura constantes, poderão possuir diferentes vazões. Essa diferença vai depender do modelo, do projeto do gotejador, dos materiais usados em sua construção e do controle de qualidade com o qual é fabricado.

Segundo a ASAE (1994) e a ISO-9261 (1991), o Coeficiente de Variação de Fabricação de gotejador (CVF) é um termo usado para descrever essa variação antecipada na vazão de uma amostra de gotejadores novos, quando operados numa pressão aproximadamente igual à pressão de serviço recomendada pelo fabricante, sendo obtido pela eq. 4 : 
$\mathrm{CVF}=\frac{S}{q_{\text {med }}}$

em que :

CVF : coeficiente de variação de fabricação ;

qmed.: média da vazão dos emissores, à pressão de referência;

S: desvio padrão da vazão de uma amostra adequada de gotejadores novos, testados na pressão de serviço normal.

Segundo Hillel (1982), o CVF pode classificar os emissores, de acordo com os seguintes valores para tubos gotejadores: (a) $\mathrm{CVF}$ até $10 \%$, bons; (b) CVF entre 10 e $20 \%$, médios; (c) CVF acima de $20 \%$, deficientes e inaceitáveis

Sabendo-se que a questão do entupimento de emissores na irrigação por gotejamento constitui um importante problema que se enfrenta há algum tempo, objetivou-se com este trabalho estudar a intensidade da ocorrência de precipitados químicos em dois tipos de tubos gotejadores (Integrados- "Tapes"- modelos C, $\mathrm{Q}$ e R e Chatos- "Flat"- modelos $\mathrm{Na}$ e $\mathrm{Ne}$ ), ao longo das horas de irrigação, quando submetidos a uma água rica em sais de ferro, inferindo-se se a água utilizada naquela oportunidade foi ou não adequada à irrigação. Dentro das condições do trabalho, analisou-se também se os aspectos construtivos peculiares de cada modelo de tubo gotejador adotado poderia estar relacionado com a sua maior ou menor vulnerabilidade e ao entupimento.

Não se deve deixar de ressaltar que não foi objetivo do trabalho avaliar marcas comerciais e sim os aspectos construtivos dos emissores, por isso os tubos gotejadores foram representados simplesmente por letras.

\section{MATERIAL E MÉTODOS}

Este trabalho foi desenvolvido no Setor de Plantas Medicinais do Departamento de Agricultura da Universidade Federal de Lavras (UFLA) na cidade de Lavras, Minas Gerais, cujas coordenadas geográficas são: $21^{\circ} 15^{\prime}$ de latitude sul e $45^{\circ} 00^{\prime}$ de longitude oeste.

$\mathrm{O}$ experimento foi conduzido em uma casa-de-vegetação (piso nivelado) com $10 \mathrm{~m}$ de comprimento por $5 \mathrm{~m}$ de largura, cobertura em sombrite, com área construída de $50 \mathrm{~m}^{2}$.

O sistema foi de irrigação foi composto de um conjunto motobomba com potência de $0,5 \mathrm{cv}$, uma bomba centrífuga BC-96, um filtro de disco de 120 mesh e um reservatório de $1000 \mathrm{~L}$.

No que diz respeito ao sistema de filtração adotado, deve-se salientar que o ideal seria a utilização de um filtro de 200 mesh, tendo em vista às exigências de alguns dos modelos de tubos gotejadores empregado Entretanto, usou-se um com 120 mesh por não se ter conseguido o recomendado à época de instalação do experimento. Ressalta-se, então, que a filtração realizada durante toda a pesquisa esteve aquém daquela recomendada pelos fabricantes.

A bancada de teste foi construída com cantoneiras e chapa com comprimento de $5,40 \mathrm{~m}$, largura de $1,20 \mathrm{~m}$ e altura de $0,30 \mathrm{~m}$, apoiada sobre roldanas. Sobre a bancada, foram instalados cinco modelos de tubos gotejadores (C, Na, Ne, Q e R).

No início de cada linha de tubos gotejadores, foram instalados pontos para tomada de pressão.

Foi empregado Manômetro tipo Bourdon, pré-aferido, para controle da pressão de trabalho de $68,67 \mathrm{kPa}$ (7 m.c.a.). Esse nível de pressão representou um valor adequado para os cinco modelos de tubos gotejadores utilizados. Além disso, foram utilizadas válvulas reguladoras de pressão da marca Bermad (para a faixa de trabalho de 49,05 a 98,1 kPa).

Foram avaliados cinco modelos de tubos gotejadores (Tabela 3 ) submetidos a uma água rica em compostos de ferro $\left(3 \mathrm{mg} . \mathrm{L}^{-1}\right.$ de ferro total). 
TABELA 3. Descrição técnica dos modelos de tubos gotejadores usados no experimento.

\begin{tabular}{|c|c|c|c|c|c|c|}
\hline Modelo & Parede (mil) & DI(mm) & $\mathbf{S}(\mathbf{c m})$ & $\begin{array}{c}\mathbf{Q} \\
\left(\mathbf{L ~ h}^{-1} \mathbf{x} \text { got.) }\right.\end{array}$ & $\begin{array}{c}\text { Pressão } \\
(\mathbf{k P a})\end{array}$ & $\begin{array}{c}\text { Filtração } \\
\text { mínima(mesh) }\end{array}$ \\
\hline $\mathrm{C}$ & 15 & 15,8 & 20 & 0,74 & 68,67 & 200 \\
\hline $\mathrm{Na}$ & 11 & 15,8 & 30 & 1,42 & 68,67 & 120 \\
\hline $\mathrm{Ne}$ & 6 & 16,1 & 20 & 0,89 & 68,67 & 120 \\
\hline $\mathrm{Q}$ & 8 & 16,5 & 11 & $0,44^{1}$ & 49,05 & 120 \\
\hline $\mathrm{R}$ & 9 & 16,0 & 20 & 1,10 & 68,67 & 200 \\
\hline
\end{tabular}

Fonte: Catálogo dos fabricantes 1 Dados de vazão a 68,67 kpa não disponível

em que:

DI: Diâmetro interno (mm)

S: Espaçamento entre emissores $(\mathrm{cm})$

Q: Vazão $\left(L \cdot h^{-1}\right)$

$1 \mathrm{mil}: 0,0254 \mathrm{~mm}$

Para se avaliar o desempenho dos tubos gotejadores, foram utilizados segmentos de tubos com 25 emissores cada um, de acordo com a norma ISO-9261 (1991). Ressalta-se que todos os modelos utilizados no trabalho funcionaram sem válvula de drenagem no final das linhas, válvulas essas que permitiriam uma melhor manutenção do sistema.

Esses tubos gotejadores foram dispostos em nível (espaçados $20 \mathrm{~cm}$ um do outro) sobre uma bancada de testes de chapas metálicas providas de rodas, que se deslocavam sobre trilhos, para viabilizar o gotejamento de todos os emissores no interior dos recipientes de coleta. Sendo que os emissores ficavam voltados para baixo.

A coleta era realizada semanalmente, em frascos plásticos com volume aproximado de $300 \mathrm{~mL}$, durante o período de 5 minutos, a uma pressão de $68,67 \mathrm{kPa}$ (7 m.c.a.). Após cada coleta, procedia-se a pesagem (para maior exatidão) em balança com precisão de 0,01 g no Laboratório de Controle da PoluiçãoDEG/UFLA. O peso obtido era transformado em volume, desconsiderando a variação da viscosidade da água (massa específica como sendo de $\left.1 \mathrm{~g} \cdot \mathrm{cm}^{-3}\right)$.

\section{Vazão relativa (V.R.)}

A Vazão Relativa foi calculada utilizandose a equação 5 :

$\mathrm{VR}=\frac{Q_{X, Y}}{Q_{i}}$

em que :

Q x,y: Vazão de um emissor $X$ num dia $Y$ de irrigação;

Qi: Vazão desse emissor no primeiro dia de irrigação.

Utilizou-se como fonte de água para os trabalhos, água da Represa localizada no Departamento deZootecnia (UFLA) no Campus da UFLA. Essa água possuía um teor natural de ferro em tomo de $0,5 \mathrm{mg} . \mathrm{L}^{-1}$, no início dos trabalhos, variando ao longo dos testes. Como a pesquisa foi conduzida com um teor fixo em $3 \mathrm{mg} . \mathrm{L}^{-1}$, somente foi acrescentado o complemento. A metodologia de análise de ferro seguiu a proposta por AWWA e WPCF(1989)

O teor citado anteriormente foi escolhido basicamente, levando-se em conta a Tabela 1, que considera como alto o risco de entupimento as águas com teor de ferro total acima de $1,5 \mathrm{mg} . \mathrm{L}^{-1}$. A utilização de uma água dessa qualidade neste estudo representa uma situação que infelizmente ocorre no campo.

A uniformidade de Distribuição/Emissão foi calculada pelo uso da equação 3 . 
Os valores de vazão foram obtidos por meio de planilha eletrônica seguindo o seguinte roteiro: (a) Após o cálculo das vazões aplicadas por cada emissor, colocaram-se em ordem crescente esses valores, utilizando-se a Equação 6; (b)Para cada coleta de água realizada, obteve-se um valor de U.E. (U.D) de cada modelo de tubo gotejador.

\section{RESULTADOS E DISCUSSÃO}

\section{Vazão média}

Pode-se observar pela Figura 1 que os precipitados químicos de ferro provocaram uma redução da vazão média em todos os cinco modelos de tubos gotejadores utilizados nos testes, concordando com Nakayama e Bucks (1986), Hemandez e Petinari (1998).

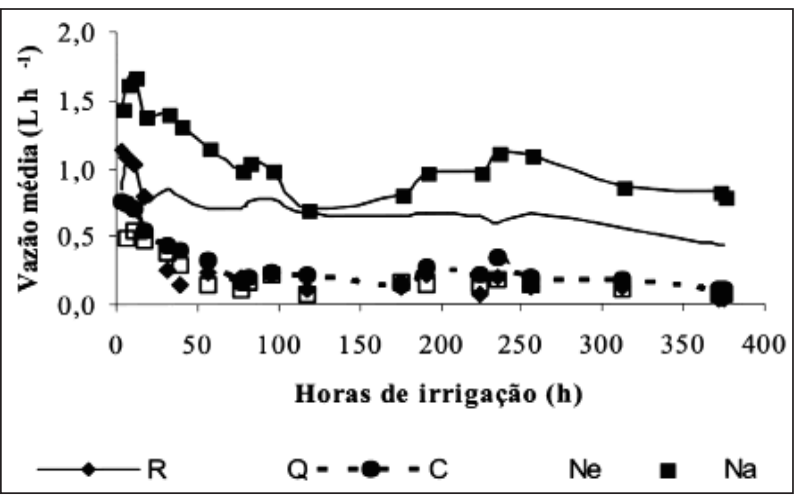

FIGURA 1 - Comportamento da Vazão Média $\left(\mathrm{L}^{\mathrm{h}} \mathrm{h}^{-1}\right)$ dos tubos gotejadores em função do tempo de funcionamento.

Essa redução apresentou um comportamento diferenciado para cada modelo de tubo gotejador, concordando com o observado por Moraes (1984) ou seja, as características construtivas são diferentes em cada um e a intensidade de entupimento se mostrou de forma heterogênea também.

O modelo $\mathrm{Na}$ iniciou os trabalhos com uma vazão de $1,44 \mathrm{~L} \cdot \mathrm{h}^{-1}$ e no final (375h) a vazão ficou reduzida para $0,80 \mathrm{~L} . \mathrm{h}^{-1}$, representando uma redução média de $46 \%$. Houve algumas oscilações importantes de vazão ao longo dos testes entre 6 e 11 h, 81 e 312 h de irrigação, correspondendo provavelmente a alterações de temperatura da água.

$\mathrm{O}$ modelo $\mathrm{Ne}$ apresentou uma redução média de vazão de $34 \%$, apresentando basicamente uma oscilação importante logo no início dos testes (entre 3 e $32 \mathrm{~h}$ ).

$\mathrm{O}$ modelo $\mathrm{C}$ teve uma queda média de vazão de $74 \%$, exibindo oscilações importantes em torno das 96,191 e 235 horas de funcionamento.

Os modelos da R e Q apresentaram as maiores reduções percentuais de vazão média ( 87 e $80 \%$, respectivamente), provavelmente pelas semelhanças nos aspectos construtivos (Labirintos), concordando com Pizarro Cabello (1996).

O tubo gotejador da $\mathrm{R}$ mostrou uma redução brusca na vazão média nas primeiras 39 horas de funcionamento, caindo de 1,14 L.h ${ }^{-1}$ para 0,14 L.h ${ }^{-1}$, apresentando, com isso, maior susceptibilidade ao entupimento.

\section{Coeficiente de variação de vazão (C.V.Q.)}

No presente trabalho, os precipitados de ferro afetaram de forma diferenciada os emissores de um mesmo modelo, ou seja, a intensidade de entupimento não foi igual em cada emissor.

As precipitações iam ocorrendo de forma aleatória dentro do tubo gotejador, onde, dos 25 emissores, alguns recebiam mais precipitados que outros, propiciando uma resposta diferenciada que se refletia na vazão. Alguns fatores, como variação de velocidade da água e variação de pressão dentro do tubo gotejador, poderiam estar contribuindo para tal ocorrência, sem levar em conta também a própria variação de vazão intrínseca de cada emissor (C.V.F.)

No início dos testes, o C.V.F. mostrou-se inferior a $6 \%$ em todos os modelos de tubos gotejadores, (exceto o Q, que mostrou um valor de $14,39 \%$ ) podendo ser classificados 
como bons e o Q como Médio, conforme sugerem Hillel (1982) e ASAE (1994), sendo que no final dos trabalhos o C.V.Q. máximo encontrado foi de 247,17\% no modelo R.

Pode-se constatar pela Figura 1 que as precipitações químicas de ferro reduziram intensamente a vazão dos tubos gotejadores, em conformidade com Moraes (1984), e que essas precipitações ocorreram de forma gradual, conforme Leite (1995) observaram para compostos calcários

Pela Figura 2 observa-se também que houve oscilações do C.V.Q. em todos os modelos estudados, e que aqueles que tiveram uma tendência de aumento mais uniforme no C.V.Q. foram o $\mathrm{Ne}$ e o Na. Modelos como Q, $\mathrm{R}$ e o C tiveram um comportamento inconstante (maior número de oscilações ao longo dos dias de testes), causado, provavelmente, por desobstruções aleatórias de emissores, conforme constatado também por Leite (1995).

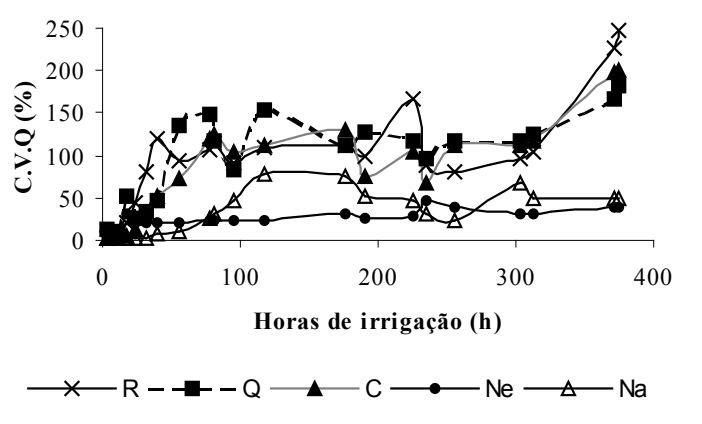

FIGURA 2 - Comportamento do Coeficiente de Variação de Vazão(C.V.Q.) dos tubos gotejadores em função do tempo de funcionamento.

No final dos testes observou-se um C.V.Q. médio de $200,51 \% ; 50,70 \% ; 40,27 \%$; $182,21 \% ; 247,17 \%$ para os modelos $\mathrm{C}, \mathrm{Na}, \mathrm{Ne}$, $\mathrm{Q}, \mathrm{R}$, respectivamente.

\section{Uniformidade de distribuição / emissão} (U.D./U.E.)

Os tubos gotejadores, no início dos trabalhos, apresentaram UD na faixa de 82,49 a $97,48 \%$ (Figura 3), valores que se enquadram na classificação da ASAE (1994). Os valores encontrados foram de 97,48\%; 97,20\%; 96,80\%; $94,89 \%, 82,49 \%$, representando os modelos $\mathrm{Na}$, $\mathrm{C}, \mathrm{R}, \mathrm{Ne}$ e Q, respectivamente.

$\mathrm{O}$ tubo gotejador $\mathrm{R}$ apresentou uma redução na UD de 96,80 para $14,86 \%$, já nas primeiras 32 horas de funcionamento.

$\mathrm{O}$ modelo que demonstrou redução menos brusca na sua UD foi o $\mathrm{Ne}$, sendo que os menores valores por ele apresentados foram em tomo de $30 \%$ (235h de funcionamento). Modelos como o $\mathrm{C}, \mathrm{R}$ e Q, já quase no final dos testes (em torno de $372 \mathrm{~h}$ ), apresentavam valores nulos de UD.

Houve um comportamento variável dos cinco modelos de tubos gotejadores, contrariando uma tendência de queda, como, por exemplo: R, C, Ne e Q entre 81 e 96 horas de irrigação (entre outros intervalos) e Na entre 118 e 256 horas.

Isso ocorreu por causa de desobstruções que ocorriam espontaneamente em alguns emissores dos diferentes modelos, provavelmente em virtude de alguma sobrepressão no sistema, o que aumentava o $\mathrm{q}_{25}$, proporcionando um incremento na U.D., concordando com Leite (1995).

Finalmente, verifícou-se que todos os modelos de tubos gotejadores foram afetados em suas uniformidades de distribuição, numa intensidade diferenciada, é verdade, mas chegando a níveis inadequados para utilização na irrigação por gotejamento.

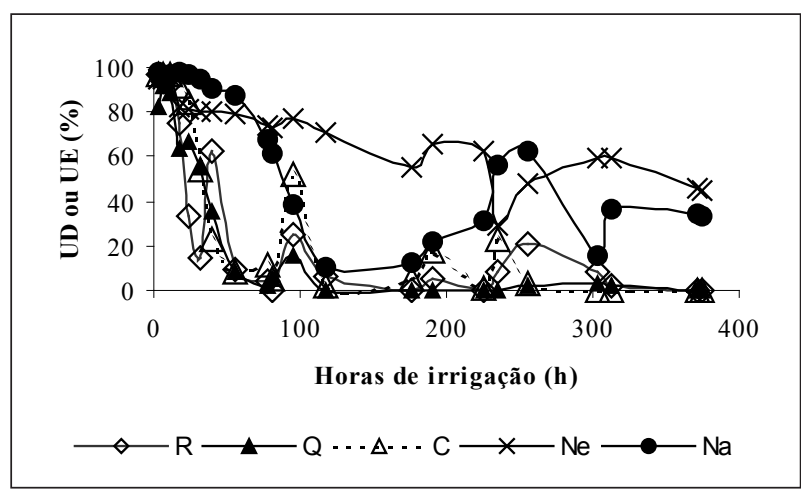

FIGURA 3 - Comportamento da uniformidade de distribuição/emissão dos tubos gotejadores em função do tempo de funcionamento. 


\section{Vazão relativa(V.R.)}

Pela Figura 4 observa-se uma clara tendência de redução da vazão relativa em todos os modelos de tubos gotejadores utilizados no estudo.

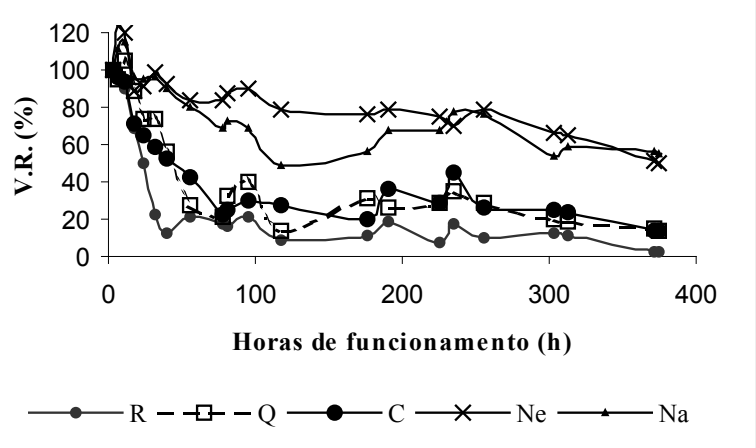

FIGURA 4 - Comportamento da vazão relativa (V.R. em \%) dos tubos gotejadores em função do tempo de funcionamento.

O modelo R apresentou uma queda na V.R. de 100 para $12,42 \%$ nas primeiras 39 horas de irrigação. A partir daí, houve oscilações até o final dos testes, quando apresentou um valor ao redor de $2 \%$ para V.R. (375h) .

Já o modelo Q mostrou duas oscilações de V.R. no início dos testes (primeiras 18 horas), e mais três aproximadamente na metade do experimento.

$\mathrm{O}$ modelo $\mathrm{C}$ teve um comportamento semelhante ao $\mathrm{R}$ nas primeiras $77 \mathrm{~h}$ de teste, ou seja, uma queda mais brusca na V.R., apresentando a partir daí, três oscilações até o final dos testes.

Houve basicamente quatro momentos de oscilação de V.R. para o Ne, sendo o mais intenso no início dos testes (primeiras $11 \mathrm{~h}$ ), em que a V.R. foi de 100 para 123,15 e depois para $119,68 \%$

$\mathrm{O}$ tubo gotejador $\mathrm{Na}$ teve uma oscilação nas primeiras $11 \mathrm{~h}$ de irrigação, com o seguinte resultado: V.R. variando de 100 para 111,58 e $115,46 \%$. E mais algumas entre 118 e $256 \mathrm{~h}$ de funcionamento.

A maior parte dessas oscilações constatadas ocorreu em virtude, provavelmente, de desobstruçoes aleatórias que ocorreram pelo efeito de alguma eventual sobrepressão no sistema e de uma influência mais acentuada da variação de temperatura na vazão (alteração da viscosidade da água), concordando com Moraes (1984) e Leite (1995).

\section{Aspectos construtivos e a ocorrência do entupimento}

Ao se proceder a uma análise do comportamento da Vazão média de irrigação, do Coeficiente de Variação de Vazão (C.V.Q.), da Uniformidade de Distribuição/Emissão de água e das vazões relativas dos cinco tubos gotejadores utilizados no estudo, suspeita-se de que as peculiaridades construtivas de cada um foram relevantes e decisivas no desempenho constatado.

Os modelos R, Q e C, que apresentam mecanismo dissipador de energia (Labirinto) bem semelhantes- Gotejadores Integrados ("Tapes"), mostraram-se mais susceptíveis ao entupimento. Os modelos $\mathrm{Ne}$ e o $\mathrm{Na}$, por serem gotejadores planos ("Flat"), têm o mecanismo diferenciado daqueles citados anteriormente, mostrando menor susceptibilidade ao entupimento.

Observando-se separadamente os modelos Q e R, e levando-se em conta os itens vazão e filtração mínima, pode-se inferir que o primeiro apresenta maior diâmetro mínimo de passagem do que o segundo, tendo em vista que o modelo Q exige filtros de 120 mesh (partículas de 130 mícrons) e o modelo da R utilizado exige filtros de 200 mesh (partículas de 75 mícrons), sugerindo-se que, neste trabalho, o aspecto de "diâmetro mínimo" mostrou-se como um fator decisivo ao entupimento, conforme relata também Pizarro Cabello (1996).

\section{CONCLUSÕES}

$\checkmark$ Os resultados encontrados permitem as seguintes conclusões:

$\checkmark$ Dentro das condições em que ocorreu o estudo, conclui-se que o uso de águas com teor de $3 \mathrm{mg} . \mathrm{L}^{-1}$ de ferro total no gotejamento, 
sem tratamento prévio, pode ser considerado inviável, pois ocorrerá comprometimento do desempenho dos emissores.

$\checkmark$ Os cinco modelos de tubos gotejadores utilizados no trabalho, na prática, não devem ser empregados dessa forma, pois sofreram intenso entupimento;

$\checkmark \mathrm{O}$ aspecto construtivo parece influenciar a resistência ao entupimento, sendo os tubos gotejadores planos ("Flat") mais resistentes do que os tubos gotejadores integrados (Tapes);

$\checkmark$ Os resultados apresentados não são passíveis de comparação, uma vez que não houve filtração adequada para alguns modelos de tubos gotejadores, nem mesmo foram utilizadas válvulas de drenagem, como é recomendado por seus fabricantes.

\section{RECOMENDAÇÕES}

Tendo-se consciência que muito ainda deve ser pesquisado no campo da qualidade de água para irrigação localizada, algumas recomendações podem ser feitas, tendo em vista futuros estudos a serem realizados.

Dentre os vários encaminhamentos que se pode dar às pesquisas, neste caso específico, recomendam-se dois:

a) Comparação do filtro de disco, de tela e de areia para águas com vários teores de ferro, nas vazões recomendadas pelos fabricantes;

b) No que diz respeito ao filtro de areia, estudar o tempo de detenção da água no meio filtrante (areia).

\section{REFERÊNCIAS BIBLIOGRÁFICAS}

AMERICAN SOCIETYOFAGRICULTURAL ENGINEERS (ASAE/EP-405.1). Standards: engineering pratices. Saint. Joseph, 1994. 819p.

AMERICAN PUBLIC HEALTH ASSOCIATION (APHA); American Water Works Association (AWWA); Water Pollution
Control Federal (WPCF). Standard methods for examination of water and wastewater. 17.ed. Washington, 1989. 1144p.

HASSAN, F.A. Water quality for microirrigation. In: MICROIRRIGATION FÓRUM, 1999. Trabalhos apresentados... [S.I.: s.n.], 1999.

HERNANDEZ, F.B.T.; PETINARI, R.A. Qualidade da água para irrigação localizada. In: CONGRESSOBRASILEIRODEENGENHARIA AGRÍCOLA, 27., 1998, Poços de Caldas. Anais... Lavras: UFLA/SBEA,1998. v.2,p. 58-60.

HILLEL, D. Advances in irrigation. New York: Academic Press, 1982. v.1, 302p.

INTERNATIONAL ORGANIZATIONS FOR STANDARDIZATION (ISO/9261). Agricultural irrigation equipment-emitting-pipe systemsspecifícation and test methods. [S.1], 1991. 7p.

KELLER, J.; KARMELI, D. Trickle irrigation design. Califórnia: Rain Bird Sprinkler, 1975. 133p.

LEITE, J.A. de O. Avaliação da susceptibilidade de tubogotejadores ao entupimento por precipitados químicos de carbonato de cálcio. Lavras: UFLA, 1995. 64p. (Dissertação - Mestrado em Irrigação e Drenagem).

MERRIAN, J.L.; KELLER, J. Farm irrigation system evaluation: a guide for management. Logan: Utah State University, 1988. 27 p.

MORAES, O. Determinação do coeficiente de variação de gotejadores e sua influência na uniformidade de emissão em linhas laterais de 
irrigação por gotejamento. Piracicaba: ESALQ, 1984. 192p. (Dissertação -Mestrado em Irrigação e Drenagem).

NAKAYAMA, F.S.; BUCKS, D.A Trickle irrigation for crop production: design, operation and management. New York: Elsevier, 1986. 383p.

PIZARRO CABELLO, F. Riegos localizados de alta frecuencia. 3.ed. Madrid: Mundi-prensa,
1996. 513p.

VIEIRA, A.T. Caracterização hidráulica de um tubo gotejador. Piracicaba: ESALQ, 1996. 56p. (Dissertação - Mestrado em Irrigação e Drenagem).

WU, I.P.; GFTLIN, H.M. Drip Irrigation: design in metric units. Honolulu: University of Hawaii, 1977. 19p. (Miscelany Publication, 144). 